\title{
Article
}

\section{Are caffeine's performance-enhancing effects partially driven by its bitter taste?}

\author{
Pickering, Craig
}

Available at http://clok.uclan.ac.uk/29667/

Pickering, Craig (2019) Are caffeine's performance-enhancing effects partially driven by its bitter taste? Medical Hypotheses, 131 . p. 109301. ISSN 03069877

It is advisable to refer to the publisher's version if you intend to cite from the work. http://dx.doi.org/10.1016/j.mehy.2019.109301

For more information about UCLan's research in this area go to

http://www.uclan.ac.uk/researchgroups/ and search for <name of research Group>.

For information about Research generally at UCLan please go to http://www.uclan.ac.uk/research/

All outputs in CLoK are protected by Intellectual Property Rights law, including Copyright law. Copyright, IPR and Moral Rights for the works on this site are retained by the individual authors and/or other copyright owners. Terms and conditions for use of this material are defined in the policies page. 
Title: Are caffeine's performance-enhancing effects partially driven by its bitter taste?

Authors: Craig Pickering ${ }^{1}$

1. Institute of Coaching and Performance, School of Sport and Wellbeing, University of Central Lancashire, Preston, UK

Corresponding Author:

Craig Pickering

Institute of Coaching and Performance, School of Sport and Wellbeing, University of Central Lancashire, Fylde Road, Preston, PR1 2HE, UK.

Email: craigpickering1014@hotmail.com 


\title{
Are caffeine's performance-enhancing effects partially driven by its bitter taste?
}

\author{
Abstract: \\ Caffeine is a well-established ergogenic aid, with its performance-enhancing effects \\ replicated across a variety of exercise types. Caffeine exerts its performance-benefits through \\ many mechanisms, including acting as an adenosine receptor antagonist, and serving to \\ reduce sensations of fatigue and pain. One potential mechanism that is currently \\ underexplored is whether caffeine's bitter taste mediates some of its ergogenic effects, which \\ is discussed in this article. Previous research has demonstrated that bitter tastants have the \\ ability to enhance performance, and this effect is mediated by bitter taste receptors in the \\ mouth and gastrointestinal tract. Additionally, the ability to detect bitter tastes is subject to \\ individual variation, raising the potential that the demonstrated inter-individual response to a \\ standardised caffeine dose is potentially driven by differences in taste response. Finally, it \\ appears that some of caffeine's performance-enhancing effects are driven by expectancy. As \\ bitter taste may serve as a signal that caffeine has been ingested, it is possible that some of \\ the expectancy effects of caffeine ingestion are driven by its bitter taste. These aspects all \\ have potentially important implications for future research, as well as for how athletes and \\ coaches utilise caffeine around competition, both of which are explored in depth here.
}




\section{Introduction}

Caffeine is a well-established ergogenic aid, with its performance benefits established across a variety of meta-analyses (1). Caffeine has a reliable and replicated ergogenic effect on endurance performance (2-7), muscular endurance (8), muscular strength and power (913), and sporting performance $(14,15)$. Whilst caffeine has the potential to exhibit ergogenic effects on sprint performance (16-20), the findings at meta-analysis level have so far been equivocal $(21,22)$. Recently, caffeine's performance benefits have been demonstrated across a range of specific sports (23), such as soccer (24), rugby (16,25), basketball (26), volleyball (27), and swimming $(17,28)$. Accordingly, there is a high frequency of caffeine use around sporting competition, with recent research suggesting around $75 \%$ of athletes do so (29). Whilst doses of 3-6 mg/kg are found to elicit the optimal ergogenic effect (30), lower doses of caffeine also have the potential to be ergogenic (31), and there is considerable variation in the "optimal" caffeine dose for athletes $(32,33)$.

Caffeine appears to exert its ergogenic effects via a variety of mechanisms. Caffeine acts as a competitive adenosine receptor antagonist (34), limiting the downregulation of arousal caused by adenosine (35). When caffeine binds to adenosine receptors, there is an increase in both neurotransmitter release and muscle firing rates (36). Caffeine also serves to stimulate adrenaline secretion (37), reduce perception of effort (38), increase sarcoplasmic calcium release (39), and decrease the perception of pain $(40,41)$, all of which have performance-enhancing potential. Additionally, caffeine enhances mental alertness (42) and mood (43), as well as ameliorating the expected performance-decrements demonstrated following a lack of sleep (44-46) and mental fatigue $(47,48)$; these factors may also serve to enhance sporting performance. 
Accordingly, much of caffeine's role in enhancing performance is well understood, although there are still some unanswered questions (49). One potential area that is currently underexplored is the role of taste as a mechanism by which caffeine may exert its performance-benefit. Caffeine is a bitter tastant (50), and there are a number of bitter taste receptors located in the oral cavity (51), which have been shown to be activated when exposed to caffeine (52). There is emerging evidence that bitter tastants may exert an ergogenic effect on exercise performance (53). In this paper, I will explore whether caffeine's bitter taste is potentially responsible for its ergogenic effects. If it is, then inter-individual variation in the ability to taste bitter compounds (52) may be, at least partially, responsible for the observed individual variation in response to caffeine supplementation on performance $(32,33)$. Furthermore, there is evidence that caffeine's ergogenic effects are partially mediated via expectancy (54-56). If the ability to detect caffeine's bitter taste affects performance, then there is the potential that this is further driven via expectancy, an aspect explored later in the paper.

\section{Are bitter tastants ergogenic?}

Caffeine is a well-established bitter tasting compound, with oral caffeine intake shown to stimulate a number of bitter taste receptors (50). Bitter tastants themselves have been shown to be ergogenic, with the leading review in this area authored by Gam and colleagues (53). Here, the authors noted that the evidence suggests that carbohydrate mouth swilling enhances performance $(57,58)$; as the carbohydrate is not ingested, the demonstrated performance enhancement may be centrally mediated. In this case, carbohydrate receptors in the mouth, associated with sweet tastes, appear to activate particular regions in the brain, 
leading Gam and colleagues (53) to explore whether other tastes drive the same response. This is especially pertinent from the perspective of caffeine, as bitter solutions have been demonstrated to elicit large and long-lasting changes within the autonomic nervous system (59), potentially due to evolutionary protective mechanisms designed to prevent ingestion of toxic substances $(60,61)$.

This hypothesis has been explored experimentally. Gam and colleagues (62) utilised quinine, a bitter agent found in tonic water, in a mouth wash immediately prior to a maximal 30 -second cycle sprint in a group of male cyclists. Here, the quinine solution was rinsed for 10 seconds, and then ingested, with significant improvements in peak and mean power output compared to plain water, a sweet solution, or no solution. Subsequent research, utilising a mouth rinse only (i.e. no ingestion) (63), did not elicit a performance improvement, suggesting that ingestion is a potentially important aspect of the performance-enhancing component of the ergogenic effects of bitter tastants (64). Ingestion may be important as the upper gastrointestinal tract, and not just the mouth, also contains bitter taste receptors (64), and so consumption of caffeine may further increase the magnitude of signals from these receptors. Outside of the work of Gam and colleagues (62-64), there is little research exploring the potentially ergogenic effects of bitter taste, but the tentative results to date suggest that a bitter taste may indeed be performance enhancing (53).

An important consideration, when interpreting these results within the context of caffeine, is the strength of the bitter tastant. In their studies, Gam and colleagues (62) utilised solutions of between $2 \mathrm{mmol} / \mathrm{L}$ quinine (for rinse and ingestion [62]) to $10 \mathrm{mmol} / \mathrm{L}$ (for rinse only [63]), which is significantly greater than the concentration of quinine found in commercial solutions such as tonic water. Whilst caffeine and quinine appear to be similarly 
bitter (65), the ingestion of highly concentrated liquid forms of caffeine may prove difficult from the perspective of palatability. Furthermore, the concentrations of caffeine in commercially available caffeinated sports drinks and coffee may not be sufficient to provoke an ergogenic bitter taste response. This is of further importance when exploring the effects of a caffeinated mouth rinse on exercise performance, a relatively new field of research (66), which requires consideration as the action of rinsing caffeine around the mouth should allow caffeine to interact with the bitter taste receptors located there, potentially driving performance improvements. A small number of studies have explored the use of caffeine mouth rinsing on performance (67-73), summarized in table 1 below.

\section{Insert table 1 around here}

These equivocal results suggest there is a general trend for no demonstrated performance improvements when caffeine is rinsed around the mouth, both for endurance and high-intensity exercise. This suggests that either caffeine's bitter taste does not drive its performance benefits, that the solutions of caffeine utilised were insufficient to provoke a substantial bitter taste response, or that ingestion of the caffeine solution following mouth rinsing, similar to that of the quinine solution (64), is important. Interestingly, a number of trials (68) reported no change in plasma caffeine concentrations following a mouth rinse; whilst not unexpected, this does provide support regarding the need for subsequent ingestion of the caffeine solution as a means of harnessing a performance benefit. Outside of physical performance improvement, Pomportes et al. (74) demonstrated improvements in cognitive function during prolonged aerobic exercise following a caffeinated mouth rinse, and De Pauw and colleagues (75) suggested that a caffeine mouth rinse may enhance reaction time. Furthermore, Van Cutsem et al. (76) demonstrated the effectiveness of a caffeine mouth rinse 
on reducing mental fatigue during a cognitively challenging task. These latter results suggest that, whilst a caffeine mouth rinse without subsequent ingestion may not directly enhance physical performance, it may have a role to play in the maintenance of cognitive function, which in turn could enhance sporting performance.

In summarizing this section, there is tentative evidence that bitter tastants may exhibit ergogenic effects, as exemplified by the research on quinine (53). Additionally, these research findings suggest that the harnessing of these ergogenic effects requires stimulation of bitter taste receptors in both the mouth and gastrointestinal tract, in turn necessitating both a mouth rinse and ingestion of the bitter tastant (53). Further support for this hypothesis is given by the generally negative results on caffeine mouth rinses (with non-ingestion), which suggests that caffeine ingestion is also required.

\section{Inter-individual variation in bitter tasting ability}

In recent years there has been an increased interest in the individual variation in response to caffeine supplementation, with a number of reviews published on the subject $(32,33,77)$. The drivers of this individual variation are wide and varied, but include genetic variation $(78,79)$, habitual caffeine use (80), expectancy (54), and potentially epigenetic modifications (32).

Alongside individual variation in the ergogenic response to caffeine, the ability to detect a bitter taste is also subject to individual variation $(52,81)$. Bitter compounds are detected by taste receptor cells in the mouth, with these cells encoded by Taste 2 Receptor $(T A S 2 R)$ genes $(82,83)$. Variation in a particular TAS2R gene, TAS2R38, is associated with 
an ability to detect the bitter compounds phenylthiocarbamide (PTC) and 6-npropylthiouracil (PROP) (84), leading to some individuals, who are sensitive to these bitter tastes, to be labelled as "supertasters" (85). This variation in taste sensitivity has been associated with variation in consumption of alcohol $(84,86)$, coffee $(86)$ and vegetables $(87)$, and variation in other TAS2R genes is associated with the palatability of coffee $(88,89)$. Furthermore, a number of SNPs have been associated with bitter taste reception through genome-wide association studies $(90,91)$, suggesting that the ability to taste bitter compounds, including caffeine, is partially heritable. Finally, the bitter taste response to caffeine appears to be somewhat modifiable. Repeated exposure to caffeine reduces the sensation of bitterness (92), as does smoking (93) and aging (94).

Accordingly, there is the possibility that, as caffeine is a bitter tastant, and bitter compounds have the potential to be ergogenic, the ability to detect caffeine's bitter taste, and the magnitude at which this occurs, may well explain some of the demonstrated individual variation in caffeine ergogenicity (32), although at present this is somewhat speculative and requires further exploration.

\section{Bitter taste and expectancy}

In their seminal study, Beedie and colleagues (54) demonstrated that, when informed that they had consumed a caffeine dose of $4.5 \mathrm{mg} / \mathrm{kg}$ and $9 \mathrm{mg} / \mathrm{kg}$, subjects increased their power output in a cycle ergometer test in a dose-response manner, even though they had been deceptively administered placebo as opposed to caffeine. Similar findings (e.g. Saunders et al. [55]), suggest that, if an individual believes they have consumed caffeine, and they believe that caffeine is ergogenic, they will potentially experience a performance benefit, even if no 
physiologically active substance has been consumed. The expectancy-derived ergogenic effect of caffeine has been demonstrated across a variety of exercise types, including aerobic endurance $(54,55,95)$ and muscular strength and endurance (96-98), along with improvements in cognitive function $(99,100)$, reaction time $(101)$, and mood $(102,103)$.

Placebos have been extensively shown to be effective in the management of pain (104), and one of the methods through which this occurs is by providing an expectation of pain relief (105). As one of the proposed mechanisms by which caffeine enhances performance is via a reduction in pain (106) and RPE (38), it's clear to see that belief of caffeine ingestion may directly influence this pathway. The bitter and recognizable taste of caffeine represents a clear signal that caffeine is being consumed, and, if the athlete believes that caffeine is ergogenic - either through information provided by a coach or nutritionist, or prior experience - then they may expect performance to improve. Furthermore, ritualistic behaviours also appear to enable placebo/expectancy effects within athletes (107). In this case, the pre-competition consumption of a caffeine substance that stimulates bitter taste receptors may have the dual performance-benefit of the athlete recognizing the ritualistic behavior (i.e. consumption of a specific brand of sports drink) and bitter taste, remembering that these two signals are associated with enhanced performance, an effect potentially accentuated by previously enhanced performance following caffeine ingestion. Whilst taste represents just one way that caffeine intake may be signaled to the athlete, along with selfrated changes in mood (54), motivation (101), and an increased perception of physiological arousal (101), it represents an interesting avenue for future exploration. As such, there is the potential that caffeine's ergogenic effects, previously demonstrated to be partially placebo/expectancy based $(54,56)$, may be modified by the bitter taste of caffeine driving these placebo/expectancy effects. Furthermore, inter-individual variation in the ability to 
detect caffeine's bitter taste may in turn affect the magnitude and occurrence of placebo/expectancy following caffeine ingestion, as may individual susceptibility to placebo (108). Tentative evidence regarding the ergogenic effects of decaffeinated coffee $(109,110)$ demonstrate the potential of expectancy and placebo - potentially mediated by bitter tasteto enhance performance within the context of caffeine. Additionally, recent research (111) suggests that cues related to coffee increase arousal without a need for coffee ingestion, further strengthening this hypothesis.

\section{What is bitter taste?}

As detailed in section 2, caffeinated mouth rinses appear to have the potential to enhance exercise performance (62), but only when the caffeine is subsequently ingested (64). One of the key potential explanations for this difference in effect between protocols is that stimulation of bitter receptors in the upper GI tract—and not just on the tongue — is an important driver of caffeine's ergogenic effects (64). This raises the question of how we define "taste" within this context, as the bitter receptors in the upper GI tract are not necessarily linked to gustatory neurons (112); this means that, whilst the activation of the bitter receptors in the upper GI may be important, we do not "taste" the bitterness in this scenario. In terms of caffeine use in sport, this could be important, given that caffeine is often consumed in energy and/or sports drink form; here, the addition of carbohydrates and other ingredients masks the bitter taste of caffeine, potentially modifying the perception of bitterness (i.e. the expectancy effect detailed in section 4), but not the activation of bitter receptors contained within the mouth and upper GI tract. Accordingly, it is important to consider that "bitterness" can therefore be comprised of both taste (i.e. the stimulation of 
gustatory neurons) and the activation of bitter receptors - with the two not always occurring in conjunction.

\section{Conclusion}

In pulling the various threads discussed in this article together, we can tentatively conclude that:

1. Caffeine is a bitter tastant (50).

2. Bitter tastants have the potential to be ergogenic (53), although this ergogenic benefit may require ingestion (64), and not merely mouth rinsing (63), with the additional caveat that, at present, this research is primarily focused around quinine and not caffeine.

3. Non-ingestion of caffeine, in the form of a mouth rinse, appears to be insufficient to evoke an ergogenic response (table 1). This is potentially surprising, given the fact that adenosine receptors are found in the mouth (113), and that caffeine can be absorbed by the buccal membrane (66). However, the limited period of time that caffeine is present in the oral cavity during a mouth rinse (typically $\sim 10$ seconds) may explain this, given that caffeine absorption in the gut typically takes $\sim 45$ minutes (114). As such, a caffeine mouth rinse likely does not provide sufficient time for the caffeine to be adequately absorbed via the buccal membrane, which is supported by the lack of a rise in plasma caffeine concentrations following a caffeine mouth rinse in some investigations (68). 
4. However, evidence suggests that some of caffeine's ergogenic benefits are partially mediated via expectancy $(54,56)$, and there is the potential that recognition of this bitter taste when consuming caffeine may support its performance enhancing effects.

Additionally, there is considerable variation in the ability to taste bitterness between humans (115), as well as considerable variation in the ergogenic response to a standardised caffeine dose (32). Accordingly, in serving to enhance our knowledge of optimal caffeine strategies in sport (49), further research should seek to explore; a) whether bitter taste detection is responsible for some of caffeine's ergogenic effects, b) whether variation in the ability to detect bitter taste modifies caffeine's performance benefits, and c) what factors, such as genotype and dietary history, affect this bitter taste response. Furthermore, from the perspective of caffeine mouth rinse research, increasing the concentration of the caffeine within the solution (to potentially harness the bitter taste), and subsequent ingestion of the caffeine solution, should be explored to determine whether this caffeine use method holds utility. In terms of exploring the individual variation in caffeine's ergogenic effects, and whether these are driven by variation in bitter taste receptors (section 3), it would be useful to explore whether variation in TAS2R genes, such as $T A S 2 R 38$, is associated with differences in the magnitude of caffeine's ergogenic effects.

From a practical perspective, coaches and athletes should be aware of the potential impact of expectancy on caffeine's ergogenic effects. This suggests that a standardised caffeine intake routine around competition, and possibly training, could be important, as the provision of regular routines may enhance any potential expectancy effects derived from caffeine: i.e., if the athlete is undertaking a behaviour that has previously delivered success, this may "prime" future success. Additionally, if the hypothesis developed here-that 
caffeine's bitter taste has the potential to enhance performance, if only via expectancy - then the mechanism of caffeine intake may become important. Whilst coffee is a relatively impractical method of caffeine ingestion, given that it is often consumed hot, requires large liquid volumes to deliver an ergogenic dose of caffeine, and has variable caffeine doses $(116,117)$, it is a highly bitter substance, more so than caffeine alone (118). Accordingly, an argument could be made that coffee's bitter taste may provide additional performance benefits, and athletes should perhaps utilise caffeine intake strategies that stimulate taste receptors, such as the use of liquids or gum, as opposed to caffeine capsules. From a safety perspective, it is important to consider that bitter tastants such as caffeine and quinine have significant "off-target" effects. In terms of caffeine, this can include increased anxiety (119) and sleep latency (120), but quinine too has the potential to induce negative side effects such as cardiac arrythmia (121), along with inhibition of potassium channels and cellular gap junctions $(122,123)$. As such, the use of concentrated bitter tastants above the concentrations found in commercially available beverages should be cautioned against.

Finally, the hypothesis forwarded here, along with other unresolved issues regarding the use of caffeine in sport (49), suggest that, whilst it may be tempting to believe that we know all there is to know about caffeine as a performance enhancer, there is still a long way to travel on this journey. In unravelling some of the complexities surrounding caffeine use, we have the potential to further enhance performance over the years to come.

\section{Conflict of Interest Statement}

Craig Pickering is a former employee of DNAFit Life Sciences a genetic testing company. He received no financial incentives for the preparation of this manuscript. 


\section{References:}

1. Grgic J, Grgic I, Pickering C, Schienfeld B, Bishop D, Pedisic Z. Wake up and smell the coffee: Caffeine supplementation and exercise performance - an umbrella review of 21 published meta-analyses. Br J Sports Med. 2019; doi: 10.1136/bjsports-2018100278

2. Christensen PM, Shirai Y, Ritz C, Nordsborg NB. Caffeine and bicarbonate for speed. A meta-analysis of legal supplements potential for improving intense endurance exercise performance. Front Physiol. 2017;8:240.

3. Conger SA, Warren GL, Hardy MA, Millard-Stafford ML. Does caffeine added to carbohydrate provide additional ergogenic benefit for endurance? Int J Sport Nutr Exerc Metab. 2011;21(1):71-84.

4. Doherty M, Smith PM. Effects of caffeine ingestion on exercise testing: a metaanalysis. Int J Sport Nutr Exerc Metab. 2004;14(6):626-46.

5. Gonçalves Ribeiro B, Pontes Morales A, Sampaio-Jorge F, de Souza Tinoco F, Alegre de Matos A, Costa Leite T. Acute effects of caffeine intake on athletic performance: A systematic review and meta-analysis. Revista Chilena de Nutrición. $2017 ; 44(3)$

6. Shen JG, Brooks MB, Cincotta J, Manjourides JD. Establishing a relationship between the effect of caffeine and duration of endurance athletic time trial events: A systematic review and meta-analysis. J Sci Med Sport. 2019;22(2):232-238

7. Southward K, Rutherfurd-Markwick KJ, Ali A. The effect of acute caffeine ingestion on endurance performance: a systematic review and meta-analysis. Sports Med. 2018;48(8):1913-1928 
8. Polito MD, Souza DB, Casonatto J, Farinatti P. Acute effect of caffeine consumption on isotonic muscular strength and endurance: a systematic review and meta-analysis. Sci Sports. 2016;31(3):119-28.

9. Grgic J. Caffeine ingestion enhances Wingate performance: a meta-analysis. Eur J Sport Sci. 2018;18(2):219-25.

10. Grgic J, Mikulic P. Caffeine ingestion acutely enhances muscular strength and power but not muscular endurance in resistance-trained men. Eur J Sport Sci. 2017;17(8):1029-36.

11. Grgic J, Pickering C. The effects of caffeine ingestion on isokinetic muscular strength: A meta-analysis. J Sci Med Sport. 2019;22(3):353-360.

12. Grgic J, Trexler ET, Lazinica B, Pedisic Z. Effects of caffeine intake on muscle strength and power: a systematic review and meta-analysis. J Int Soc Sports Nutr. 2018;15(1):11.

13. Grgic J, Mikulic P, Schoenfeld BJ, Bishop DJ, Pedisic Z. The influence of caffeine supplementation on resistance exercise: A review. Sports Med. 2019;49(1):17-30.

14. Ganio MS, Klau JF, Casa DJ, Armstrong LE, Maresh CM. Effect of caffeine on sportspecific endurance performance: a systematic review. J Strength Cond Res. 2009;23(1):315-24

15. Astorino TA, Roberson DW. Efficacy of acute caffeine ingestion for short-term highintensity exercise performance: a systematic review. J Strength Cond Res. 2010;24(1):257-65.

16. Del Coso J, Portillo J, Muñoz G, Abián-Vicén J, Gonzalez-Millán C, Muñoz-Guerra J. Caffeine-containing energy drink improves sprint performance during an international rugby sevens competition. Amino Acids. 2013;44(6):1511-9. 
17. Collomp K, Ahmaidi S, Chatard JC, Audran M, Prefaut C. Benefits of caffeine ingestion on sprint performance in trained and untrained swimmers. Eur J Appl Physiol Occup Physiol. 1992;64(4):377-80.

18. Schneiker KT, Bishop D, Dawson B, Hackett LP. Effects of caffeine on prolonged intermittent-sprint ability in team-sport athletes. Med Sci Sports Exerc. $2006 ; 38(3): 578-85$

19. Carr A, Dawson B, Schneiker K, Goodman C, Lay B. Effect of caffeine supplementation on repeated sprint running performance. J Sports Med Phys Fitness. $2008 ; 48(4): 472$.

20. Glaister M, Howatson G, Abraham CS, et al. Caffeine supplementation and multiple sprint running performance. Med Sci Sports Exerc. 2008;40(10):1835-40.

21. Brown SJ, Brown J, Foskett A. The effects of caffeine on repeated sprint performance in team sport athletes-a meta-analysis. Sport Sci Rev. 2013;22(1-2):25-32.

22. Souza DB, Del Coso J, Casonatto J, Polito MD. Acute effects of caffeine-containing energy drinks on physical performance: a systematic review and meta-analysis. Eur $\mathbf{J}$ Nutr. 2017;56(1):13-27.

23. Salinero JJ, Lara B, Del Coso J. Effects of acute ingestion of caffeine on team sports performance: A systematic review and meta-analysis. Res Sports Med. $2019 ; 27(2): 238-256$

24. Mielgo-Ayuso J, Calleja-Gonzalez J, Del Coso J, Urdampilleta A, León-Guereño P, Fernández-Lázaro D. Caffeine supplementation and physical performance, muscle damage and perception of fatigue in soccer players: a systematic review. Nutrients. 2019;11(2):440. 
25. Del Coso J, Ramírez JA, Muñoz G, et al. Caffeine-containing energy drink improves physical performance of elite rugby players during a simulated match. Appl Physiol Nutr Metab. 2012;38(4):368-74.

26. Stojanovic E, Stojiljkovic N, Scanlan AT, et al. Acute caffeine supplementation promotes small to moderate improvements in performance tests indicative of in-game success in professional female basketball players. Appl Physiol Nutr Metab. 2019. doi: 10.1139/apnm-2018-0671

27. Del Coso J, Pérez-López A, Abian-Vicen J, Salinero JJ, Lara B, Valadés D. Enhancing physical performance in male volleyball players with a caffeine-containing energy drink. Int J Sports Physiol Perform. 2014;9(6):1013-8.

28. Lara B, Ruiz-Vicente D, Areces F, et al. Acute consumption of a caffeinated energy drink enhances aspects of performance in sprint swimmers. Br J Nutr. 2015;114(6):908-14.

29. Aguilar-Navarro M, Muñoz G, Salinero JJ, Muñoz-Guerra J, et al. Urine Caffeine Concentration in Doping Control Samples from 2004 to 2015. Nutrients. 2019;11(2):286.

30. Goldstein ER, Ziegenfuss T, Kalman D, et al. International society of sports nutrition position stand: caffeine and performance. J Int Soc Sports Nutr. 2010;7(1):5.

31. Spriet LL. Exercise and sport performance with low doses of caffeine. Sports Med. 2014;44(2):175-84.

32. Pickering C, Kiely J. Are the current guidelines on caffeine use in sport optimal for everyone? Inter-individual variation in caffeine ergogenicity, and a move towards personalised sports nutrition. Sports Med 2018;48(1):7-16. 
33. Southward K, Rutherfurd-Markwick K, Badenhorst C, Ali A. The role of genetics in moderating the inter-individual differences in the ergogenicity of caffeine. Nutrients. 2018;10(10):1352.

34. Urry E, Landolt HP. Adenosine, caffeine, and performance: from cognitive neuroscience of sleep to sleep pharmacogenetics. Curr Top Behav Neurosci. 2015;25:331-66.

35. Ribeiro JA, Sebastiao AM. Caffeine and adenosine. J Alzheimers Dis. 2010;20(s1):S3-15

36. Kalmar JM. The influence of caffeine on voluntary muscle activation. Med Sci Sports Exerc. 2005;37(12):2113-9.

37. Graham TE. Caffeine and exercise. Sports Med. 2001;31(11):785-807.

38. Doherty M, Smith PM. Effects of caffeine ingestion on rating of perceived exertion during and after exercise: a meta-analysis. Scand J Med Sci Sports. 2005;15(2):69-78.

39. Sökmen B, Armstrong LE, Kraemer WJ, et al. Caffeine use in sports: considerations for the athlete. J Strength Cond Res. 2008;22(3):978-86.

40. Gonglach AR, Ade CJ, Bemben MG, Larson RD, Black CD. Muscle pain as a regulator of cycling intensity: effect of caffeine ingestion. Med Sci Sports Exerc. 2016 Feb;48(2):287-96.

41. Laurent D, Schneider KE, Prusaczyk WK, et al. Effects of caffeine on muscle glycogen utilization and the neuroendocrine axis during exercise. J Clin Endocrinol Metab. 2000;85(6):2170-5.

42. Zwyghuizen-Doorenbos A, Roehrs TA, Lipschutz L, Timms V, Roth T. Effects of caffeine on alertness. Psychopharmacology. 1990;100(1):36-9. 
43. Haskell CF, Kennedy DO, Wesnes KA, Scholey AB. Cognitive and mood improvements of caffeine in habitual consumers and habitual non-consumers of caffeine. Psychopharmacology. 2005;179(4):813-25.

44. Lieberman HR, Tharion WJ, Shukitt-Hale B, Speckman KL, Tulley R. Effects of caffeine, sleep loss, and stress on cognitive performance and mood during US Navy SEAL training. Psychopharmacology. 2002;164(3):250-61.

45. McLellan TM, Kamimori GH, Voss DM, Bell DG, Cole KG, Johnson D. Caffeine maintains vigilance and improves run times during night operations for Special Forces. Aviat Space Environ Med. 2005;76(7):647-54.

46. Cook CJ, Crewther BT, Kilduff LP, Drawer S, Gaviglio CM. Skill execution and sleep deprivation: effects of acute caffeine or creatine supplementation-a randomized placebo-controlled trial. J Int Soc Sports Nutr. 2011;8(1):2.

47. Foskett A, Ali A, Gant N. Caffeine enhances cognitive function and skill performance during simulated soccer activity. Int J Sport Nutr Exerc Metab. 2009;19(4):410-23

48. Duncan MJ, Taylor S, Lyons M. The effect of caffeine ingestion on field hockey skill performance following physical fatigue. Res Sports Med. 2012;20(1):25-36.

49. Pickering C, Grgic J. Caffeine and exercise: what next? Sports Med. 2019. (In press).

50. Poole RL, Tordoff MG. The taste of caffeine. J Caffeine Res. 2017;7(2):39-52.

51. Matsumoto I. Gustatory neural pathways revealed by genetic tracing from taste receptor cells. Biosci Biotechnol Biochem. 2013;77(7):1359-62.

52. Meyerhof W, Batram C, Kuhn C, et al. The molecular receptive ranges of human TAS2R bitter taste receptors. Chem Senses. 2010;35(2):157-70.

53. Gam S, Guelfi KJ, Fournier PA. New insights into enhancing maximal exercise performance through the use of a bitter tastant. Sports Med. 2016;46(10):1385-90. 
54. Beedie CJ, Stuart EM, Coleman DA, Foad AJ. Placebo effects of caffeine on cycling performance. Med Sci Sports Exerc. 2006;38(12):2159-64.

55. Saunders B, de Oliveira LF, da Silva RP, et al. Placebo in sports nutrition: a proof-ofprinciple study involving caffeine supplementation. Scand J Med Sci Sports. 2017;27(11):1240-7.

56. Shabir A, Hooton A, Tallis J, F Higgins M. The influence of caffeine expectancies on sport, exercise, and cognitive performance. Nutrients. 2018;10(10):1528.

57. Carter JM, Jeukendrup AE, Jones DA. The effect of carbohydrate mouth rinse on 1-h cycle time trial performance. Med Sci Sports Exerc. 2004;36(12):2107-11.

58. Jeukendrup AE, Chambers ES. Oral carbohydrate sensing and exercise performance. Curr Opin Clin Nutr Metab Care. 2010;13(4):447-51.

59. Rousmans S, Robin O, Dittmar A, Vernet-Maury E. Autonomic nervous system responses associated with primary tastes. Chem Senses. 2000;25(6):709-18.

60. Glendinning JI. Is the bitter rejection response always adaptive? Physiol Behav. 1994;56(6):1217-27.

61. Meyerhof W. Elucidation of mammalian bitter taste. Rev Physiol Biochem Pharmacol. 2005; 154:37-72.

62. Gam S, Guelfi KJ, Fournier PA. Mouth rinsing and ingesting a bitter solution improves sprint cycling performance. Med Sci Sports Exerc. 2014;46(8):1648-57.

63. Gam S, Tan M, Guelfi KJ, Fournier PA. Mouth rinsing with a bitter solution without ingestion does not improve sprint cycling performance. Eur J Appl Physiol. 2015;115(1):129-38.

64. Gam S, Guelfi KJ, Hammond G, Fournier PA. Mouth rinsing and ingestion of a bitter-tasting solution increases corticomotor excitability in male competitive cyclists. Eur J Appl Physiol. 2015;115(10):2199-204. 
65. Leach EJ, Noble AC. Comparison of bitterness of caffeine and quinine by a timeintensity procedure. Chem Senses. 1986;11(3):339-45.

66. Wickham KA, Spriet LL. Administration of caffeine in alternate forms. Sports Med. 2018;48(1):79-91.

67. Beaven CM, Maulder P, Pooley A, Kilduff L, Cook C. Effects of caffeine and carbohydrate mouth rinses on repeated sprint performance. Appl Physiol Nutr Metab. 2013;38(6):633-7.

68. Doering TM, Fell JW, Leveritt MD, Desbrow B, Shing CM. The effect of a caffeinated mouth-rinse on endurance cycling time-trial performance. Int J Sport Nutr Exerc Metab. 2014;24(1):90-7.

69. Clarke ND, Kornilios E, Richardson DL. Carbohydrate and caffeine mouth rinses do not affect maximum strength and muscular endurance performance. J Strength Cond Res. 2015;29(10):2926-31.

70. Kizzi J, Sum A, Houston FE, Hayes LD. Influence of a caffeine mouth rinse on sprint cycling following glycogen depletion. Eur J Sport Sci. 2016;16(8):1087-94.

71. Pataky MW, Womack CJ, Saunders MJ, et al. Caffeine and 3-km cycling performance: Effects of mouth rinsing, genotype, and time of day. Scand J Med Sci Sports. 2016;26(6):613-9.

72. Bottoms L, Hurst H, Scriven A, et al. The effect of caffeine mouth rinse on self-paced cycling performance. Comp Exerc Physiol. 2014;10(4):239-45.

73. Dolan P, Witherbee KE, Peterson KM, Kerksick CM. Effect of carbohydrate, caffeine, and carbohydrate+ caffeine mouth rinsing on intermittent running performance in collegiate male lacrosse athletes. J Strength Cond Res. 2017;31(9):2473-9. 
74. Pomportes L, Brisswalter J, Casini L, Hays A, Davranche K. Cognitive performance enhancement induced by caffeine, carbohydrate and guarana mouth rinsing during submaximal exercise. Nutrients. 2017;9(6):589.

75. De Pauw K, Roelands B, Knaepen K, Polfliet M, Stiens J, Meeusen R. Effects of caffeine and maltodextrin mouth rinsing on P300, brain imaging and cognitive performance. J Appl Physiol. 2015;118(6):776-82.

76. Van Cutsem J, De Pauw K, Marcora S, Meeusen R, Roelands B. A caffeinemaltodextrin mouth rinse counters mental fatigue. Psychopharmacology. 2018;235(4):947-58.

77. Fulton J, Dinas P, Carrillo A, Edsall J, Ryan E, Ryan E. Impact of genetic variability on physiological responses to caffeine in humans: A systematic review. Nutrients. 2018;10(10):1373.

78. Guest N, Corey P, Vescovi J, El-Sohemy A. Caffeine, CYP1A2 genotype, and endurance performance in athletes. Med Sci Sports Exerc. 2018;50(8):1570-8.

79. Loy BD, O'Connor PJ, Lindheimer JB, Covert SF. Caffeine is ergogenic for adenosine A2A receptor gene (ADORA2A) T allele homozygotes: a pilot study. $\mathrm{J}$ Caffeine Res. 2015;5(2):73-81.

80. Pickering C, Kiely J. What should we do about habitual caffeine use in athletes? Sports Med. 2018; doi: 10.1007/s40279-018-0980-7

81. Behrens M, Meyerhof W. Bitter taste receptor research comes of age: from characterization to modulation of TAS2Rs. Sem Cell Devel Biol. 2013;24(3):215-21

82. Adler E, Hoon MA, Mueller KL, Chandrashekar J, Ryba NJ, Zuker CS. A novel family of mammalian taste receptors. Cell. 2000;100(6):693-702.

83. Chandrashekar J, Mueller KL, Hoon MA, et al. T2Rs function as bitter taste receptors. Cell. 2000;100(6):703-11. 
84. Duffy VB, Davidson AC, Kidd JR, et al. Bitter receptor gene (TAS2R38), 6-npropylthiouracil (PROP) bitterness and alcohol intake. Alcohol Clin Exp Res. 2004;28(11):1629-37.

85. Bartoshuk LM, Duffy VB, Miller IJ. PTC/PROP tasting: anatomy, psychophysics, and sex effects. Physiol Behav. 1994;56(6):1165-71.

86. Ong JS, Hwang DL, Zhong VW, et al. Understanding the role of bitter taste perception in coffee, tea and alcohol consumption through Mendelian randomization. Sci Rep. 2018;8(1):16414.

87. Duffy VB, Hayes JE, Davidson AC, Kidd JR, Kidd KK, Bartoshuk LM. Vegetable intake in college-aged adults is explained by oral sensory phenotypes and TAS2R38 genotype. Chemosens Percept. 2010;3(3-4):137-48.

88. Hayes JE, Wallace MR, Knopik VS, Herbstman DM, Bartoshuk LM, Duffy VB. Allelic variation in TAS2R bitter receptor genes associates with variation in sensations from and ingestive behaviors toward common bitter beverages in adults. Chem Senses. 2010;36(3):311-9.

89. Pirastu N, Kooyman M, Traglia M, et al. Association analysis of bitter receptor genes in five isolated populations identifies a significant correlation between TAS2R43 variants and coffee liking. PLoS One. 2014;9(3):e92065.

90. Ledda M, Kutalik Z, Souza Destito MC, et al. GWAS of human bitter taste perception identifies new loci and reveals additional complexity of bitter taste genetics. Hum Mol Genet. 2013;23(1):259-67.

91. Roos T, Kulemin N, Ahmetov I, Lasarow A, Grimaldi K. Genome-wide association studies identify 15 genetic markers associated with marmite taste preference. BioRxiv. 2017:185629. 
92. Tanimura S, Mattes RD. Relationships between bitter taste sensitivity and consumption of bitter substances. J Sens Stud. 1993;8(1):31-41.

93. Kaplan AR, Glanville EV, Fischer R. Taste thresholds for bitterness and cigarette smoking. Nature. 1964;202(4939):1366.

94. Mennella JA, Pepino MY, Duke FF, Reed DR. Age modifies the genotype-phenotype relationship for the bitter receptor TAS2R38. BMC Genet. 2010;11(1):60.

95. Foad AJ, Beedie CJ, Coleman DA. Pharmacological and psychological effects of caffeine ingestion in 40-km cycling performance. Med Sci Sports Exerc. $2008 ; 40(1): 158$.

96. Pollo A, Carlino E, Benedetti F. The top-down influence of ergogenic placebos on muscle work and fatigue. Eur J Neurosci. 2008;28(2):379-88.

97. Duncan MJ, Lyons M, Hankey J. Placebo effects of caffeine on short-term resistance exercise to failure. Int J Sports Physiol Perform. 2009;4(2):244-53.

98. Tallis J, Muhammad B, Islam M, Duncan MJ. Placebo effects of caffeine on maximal voluntary concentric force of the knee flexors and extensors. Muscle Nerve. 2016;54(3):479-86.

99. Fillmore M, Vogel-Sprott M. Expected effect of caffeine on motor performance predicts the type of response to placebo. Psychopharmacology. 1992;106(2):209-14.

100. Elliman NA, Ash J, Green MW. Pre-existent expectancy effects in the relationship between caffeine and performance. Appetite. 2010;55(2):355-8.

101. Harrell PT, Juliano LM. Caffeine expectancies influence the subjective and behavioral effects of caffeine. Psychopharmacology. 2009;207(2):335.

102. Dawkins L, Shahzad FZ, Ahmed SS, Edmonds CJ. Expectation of having consumed caffeine can improve performance and mood. Appetite. 2011;57(3):597600. 
103. Denson TF, Jacobson M, Von Hippel W, Kemp RI, Mak T. Caffeine expectancies but not caffeine reduce depletion-induced aggression. Psychol Addict Behav. 2012 Mar;26(1):140.

104. Schafer SM, Colloca L, Wager TD. Conditioned placebo analgesia persists when subjects know they are receiving a placebo. J Pain. 2015;16(5):412-20.

105. Trojian TH, Beedie CJ. Placebo effect and athletes. Curr Sports Med Rep. 2008;7(4):214-7.

106. Motl RW, O’Connor PJ, Dishman RK. Effect of caffeine on perceptions of leg muscle pain during moderate intensity cycling exercise. J Pain. 2003;4(6):316-21.

107. Beedie CJ. Placebo effects in competitive sport: Qualitative data. J Sports Sci Med. 2007 Mar;6(1):21.

108. Hall KT, Loscalzo J, Kaptchuk TJ. Genetics and the placebo effect: the placebome. Trends Mol Med. 2015;21(5):285-94.

109. Kirsch I, Weixel LJ. Double-blind versus deceptive administration of a placebo. Behav Neurosci. 1988;102(2):319.

110. Richardson DL, Clarke ND. Effect of coffee and caffeine ingestion on resistance exercise performance. J Strength Cond Res. 2016;30(10):2892-900 111. Chan EY, Maglio SJ. Coffee cues elevate arousal and reduce level of construal. Conscious Cogn. 2019;70:57-69.

112. Rozengurt E. Taste receptors in the gastrointestinal tract. I. Bitter taste receptors and $\alpha$-gustducin in the mammalian gut. Am J Physiol Gastrointest Liver Physiol. 2006;291(2):G171-7.

113. Rubinstein I, Chandilawa R, Dagar S, Hong D, Gao XP. Adenosine A1 receptors mediate plasma exudation from the oral mucosa. J Appl Physiol. 2001;91(2):552-60. 
114. Liguori A, Hughes JR, Grass JA. Absorption and subjective effects of caffeine from coffee, cola and capsules. Pharmacol Biochem Behav. 1997;58(3):721-6.

115. Wieczorek MN, Walczak M, Skrzypczak-Zielińska M, Jeleń HH. Bitter taste of Brassica vegetables: the role of genetic factors, receptors, isothiocyanates, glucosinolates, and flavor context. Crit Rev Food Sci Nutr. 2018;58(18):3130-40.

116. Desbrow B, Hughes R, Leveritt M, Scheelings P. An examination of consumer exposure to caffeine from retail coffee outlets. Food Chem Toxicol. 2007;45(9):158892.

117. Desbrow B, Hall S, Irwin C. Caffeine content of Nespresso® pod coffee. Nutri Health. 2018:0260106018810941.

118. Hofmann T. Identification of the key bitter compounds in our daily diet is a prerequisite for the understanding of the hTAS2R gene polymorphisms affecting food choice. Ann N Y Acad Sci. 2009;1170(1):116-25.

119. Childs E, Hohoff C, Deckert J, Xu K, Badner J, De Wit H. Association between ADORA2A and DRD2 polymorphisms and caffeine-induced anxiety. Neuropsychopharmacology. 2008;33(12):2791.

120. Drake C, Roehrs T, Shambroom J, Roth T. Caffeine effects on sleep taken 0, 3, or 6 hours before going to bed. J Clin Sleep Med. 2013;9(11):1195-200.

121. Sheehan ET, Frizzell JD, Gabaldon J, West MB. Quinine and the ABCs of long QT: a patient's misfortune with arthritis,(alcoholic) beverages, and cramps. J Gen Intern Med. 2016;31(10):1254-7.

122. Imai S, Suzuki T, Sato K, Tokimasa T. Effects of quinine on three different types of potassium currents in bullfrog sympathetic neurons. Neurosci Lett. 1999;275(2):121-4. 
123. Srinivas M, Hopperstad MG, Spray DC. Quinine blocks specific gap junction channel subtypes. Proc Natl Acad Sci. 2001;98(19):10942-7 